\title{
ALOISIO MAGALHÃES E O CRUZEIRO: RELAÇÕES ENTRE O DESIGN E A NACIONALIZAÇÃO DA PRODUÇÃO DO PAPEL-MOEDA NO BRASIL
}

\author{
Airton Jordani Jardim Filho \\ Universidade do Estado de Santa Catarina \\ Universidade Federal de Santa Catarina \\ airtonjordani@gmail.com \\ Adreson Vilson Vita de Sá \\ adreson@gmail.com \\ Marshal Becon Lauzer \\ Universidade Feevale \\ ESPM-Sul \\ marshal@feevale.br
}

Resumo: O presente artigo busca traçar um panorama da relação entre Aloisio Magalhães e o processo de nacionalização da produção de cédulas de dinheiro no Brasil. Além de uma breve história do dinheiro brasileiro, esta pesquisa apresenta o trabalho do designer no desenvolvimento de um padrão monetário $100 \%$ nacional. Esta pesquisa apresenta ainda os projetos de autoria de Aloisio Magalhães para as notas de 1, 500 e 1000 cruzeiros e que, ainda hoje - passados mais de 40 anos de sua criação, seu legado anda impacta sobre a maneira de projetar notas de dinheiro no Brasil e no mundo.

Palavras-chave: Aloisio Magalhães, Dinheiro Brasileiro, Notas de Dinheiro

\begin{abstract}
This paper aims to present an overview of the relationship between Aloisio Magalhães and the nationalization process of the production of Brazilian paper money. In addition, this research presents a brief history of Brazilian money, and the designer's work developing a national monetary standard. This paper also presents the projects of 1, 500 and 1000 notes projects by Aloisio Magalhaes - more than 40 years after, his legacy stills impact on the way money notes are designed in Brazil and worldwide.
\end{abstract}

Key-words: Aloisio Magalhães, Brazilian currency, Paper money 


\section{INTRODUÇÃO}

Presente no cotidiano de todos brasileiros, as cédulas de dinheiro raramente suscitam algum tipo de reflexão a seu respeito. Notas de dinheiro são utilizadas diversas vezes durante ao dia, mas quase ninguém, de fato, presta atenção nelas. Ao entrevistar Aloisio Magalhães, em 1972, Germana de Lamare questionou: "Por que você só trabalha com coisas que ninguém presta atenção?" (LEITE, 2014, p. 57). A pergunta resume, essencialmente, a questão de desenhar cédulas de dinheiro: mesmo sendo um objeto valioso, de grande utilidade pública e diretamente relacionado à cidadania, pouca gente realmente observa e reflete sobre as notas de dinheiro. Grande parte da população, por exemplo, desconhece o processo de concepção de uma nota e menos ainda são aqueles que se perguntam sobre como funciona o processo de produção de dinheiro em papel.

Em entrevista ao jornal O Globo, em 1978, Aloisio afirmava que em nosso país, muitos têm pouco e poucos têm muito dinheiro. A distribuição de renda já era um dos assuntos mais recorrentes. "O dinheiro é um grande problema social, pois a vida social toda repousa em cima dele. Ele é um suporte material de um projeto fenomenológico muito importante. Daí a necessidade de a população se informar melhor sobre ele" (LEITE, 2014, p. 140).

Até mesmo entre os pesquisadores do campo do design gráfico no Brasil, são raros os que se dedicam a explorar esse ramo de atividade da comunicação visual tão presente na vida de todas as pessoas. Seja pelo mercado de atuação restrito, seja pela falta de oferta de disciplinas e cursos dessa área do design. No entanto,

não há homem contemporâneo que não saiba o que é dinheiro. Esse elemento da cultura material parece sempre estar presente, essa mercadoria particular que serve de medida intermediária entre todas as outras. Mercadoria que expressa narrativas do nacional coletivamente construídas (SILVA JUNIOR, 2008, p. 4).

O dinheiro é parte da identidade do país cujo nome nele está estampado. Representa, entre outras coisas, os valores de uma nação e, invariavelmente, ostenta algum de seus símbolos nacionais. É uma das peças gráficas responsáveis por difundir elementos da identidade do país, através de sua larga circulação. Rafael Cardoso Denis, ao analisar a relação entre o trabalho de Aloisio e a identidade estatal brasileira elencou as notas de dinheiro como um dos destaques. Segundo ele

Aloisio ajudou a moldar a própria face pública do estado através de projetos marcantes para a Casa da Moeda (séries de cédulas de dinheiro de 1968 a 1978), para o Sesquicentenário da Independência (1972) e para o $4^{\circ}$ Centenário da Fundação da Cidade do Rio de Janeiro (1965) (DENIS, 2000, p. 167).

O presente artigo busca, desta forma, traçar um panorama da relação entre Aloisio Magalhães e o processo de nacionalização da produção de cédulas de dinheiro no Brasil e a contribuição do desenho industrial nesse processo. 


\section{BREVE HISTÓRIA DA PRODUÇÃO DE PAPEL-MOEDA NO BRASIL}

Durante décadas, o papel-moeda circulante no Brasil era inteiramente importado. Produzido pela Thomas de La Rue e pelo American Bank Note, o dinheiro brasileiro era praticamente inviável, dado o altíssimo custo de importação e, acima de tudo, manutenção, em um país de dimensões continentais como o Brasil (TRIGUEIROS, 1987). Em entrevista ao jornal O Globo, em 1978, sobre a nacionalização da produção de nosso papel-moeda, Aloisio Magalhães afirmava:

Eu não tenho estatísticas, mas sei que pagávamos uma fábula para importar dinheiro. Num país pequeno pode ser econômico importar, pois o volume de dinheiro é pequeno, não compensa ter máquinas e todo o processo produtivo complexo e oneroso, mas em um país imenso como o nosso, em processo de desenvolvimento, fabricar dinheiro virou uma necessidade premente (LEITE, 2014, p. 141).

Afinado ao discurso de Aloisio, TRIGUEIROS (1987, p. 154), recorda que "era até humilhante para o nosso país [...] o fato de ainda não estar imprimindo sua própria moeda, com papel aqui também fabricado, pois isso dependia apenas de maquinaria e de orientação técnica".

Apesar de prevista na Lei 1.216, de 28 de outubro de 1950 - a qual modificava o regulamento da Casa da Moeda - como uma finalidade da instituição, a impressão do papel-moeda não passou de um desejo nos anos 1950. Já no final da década, o assunto voltou a baila com a publicação da portaria $n^{\circ}$. 105 (de 11 de maio de 1959) do Ministério da Fazenda, que constituia uma comissão que tinha por finalidade o estudo do problema da fabricação do papel-moeda no País. Tal comissão encerrou seus trabalhos em julho de 1959, concluindo ser necessária a criação da Fábrica Nacional de Valores. Tal criação consistia em transformar a Casa da Moeda em uma sociedade de economia mista. A Fábrica teria competência para, entre outras coisas, finalmente produzir o papel-moeda brasileiro. A história da possível criação da Fábrica Nacional de Valores S.A. teve novo capítulo em outubro de 1963, apresentada como projeto de lei, de autoria do Deputado Gil Veloso - o projeto nº 1.502, de 1963.

No entanto, com o golpe de estado ocorrido em 31 de março de 1964, os rumos da nacionalização da produção de dinheiro mudaram, novamente. O então presidente, Marechal Humberto de Alencar Castelo Branco enviou mensagem ao Congresso Nacional determinando, a reorganização da Cada da Moeda - e não a criação de uma empresa de sociedade anônima - tendo como base a Lei 4.510, de dezembro de 1964 (TRIGUEIROS, 1987).

A partir de uma série de investimentos do governo e a colaboração do Banco Central do Brasil, ocorreu uma completa reestruturação na Casa Moeda. A instituição foi equipada, dando-Ihe agilidade e subsídios para o protagonismo necessário ao processo de nacionalização da produção de papel moeda. A autossuficiência na produção das cédulas de dinheiro, no entanto, veio apenas no inicio dos anos 1970. Em entrevista ao Jornal do Brasil, em 1978, Aloisio orgulhosamente afirmava: "O mais importante, porém, é que, desde 1972, o Brasil é totalmente independente na fabricação de seu papel-moeda. Tudo é feito em casa" (LEITE, 2014, p. 125). 


\section{ALOISIO MAGALHÃES E O PROJETO DO CRUZEIRO: UM PADRÃO MONETÁRIO $100 \%$ BRASILEIRO}

Em 1966, através de um concurso fechado, Magalhães foi escolhido para iniciar o processo de nacionalização da produção de dinheiro. TRIGUEIROS (1987, p. 230-231) lembra que

em nome do Banco Central, convidou-se Alexandre Wolner, Aloisio Magalhães, Gustavo Goebel Wayne Rodrigues e Ludovico Martino. A casa da moeda indicou Benedito de Araújo Ribeiro, Petrarca Amenta, Waldir Granado e Zélio Bruno da Trindade [...]. Aloisio Magalhães desenvolveu uma nova solução gráfica, adotando o sistema "moiré" na composição dos desenhos, de modo a dificultar os processos de falsificação. Ao mesmo tempo, criou uma linha de valores de tamanhos e cores diferentes, com idênticas características, combinadas com elementos dos medalhões e rosáceas. Sem compromisso com a tradição gráfica especializada, seu trabalho ofereceu uma concepção visual nova, marcada pela afinidade ao movimento artístico brasileiro, servindo-se da cédula como elemento de comunicação de massa, genuíno da nossa cultura.

No ano seguinte, 1967, foi lançado o novo padrão monetário brasileiro. 0 primeiro passo estava dado e, pela primeira vez, as cédulas brasileiras tinham, igualmente, um desenho brasileiro.

Esse ciclo, que se inicia no concurso, se desdobra no desenvolvimento e na emissão da primeira família de cédulas do padrão Cruzeiro Novo, que representa uma vitória da ruptura sobre a tradição estética na visualidade do dinheiro brasileiro, se estenderá pela década seguinte, com a atuação de Aloisio Magalhães em outros projetos (SILVA JUNIOR, 2008, p. 128).

A autonomia na produção do dinheiro viria em 1972, quando o processo de fabricação passa a ser $100 \%$ brasileiro.

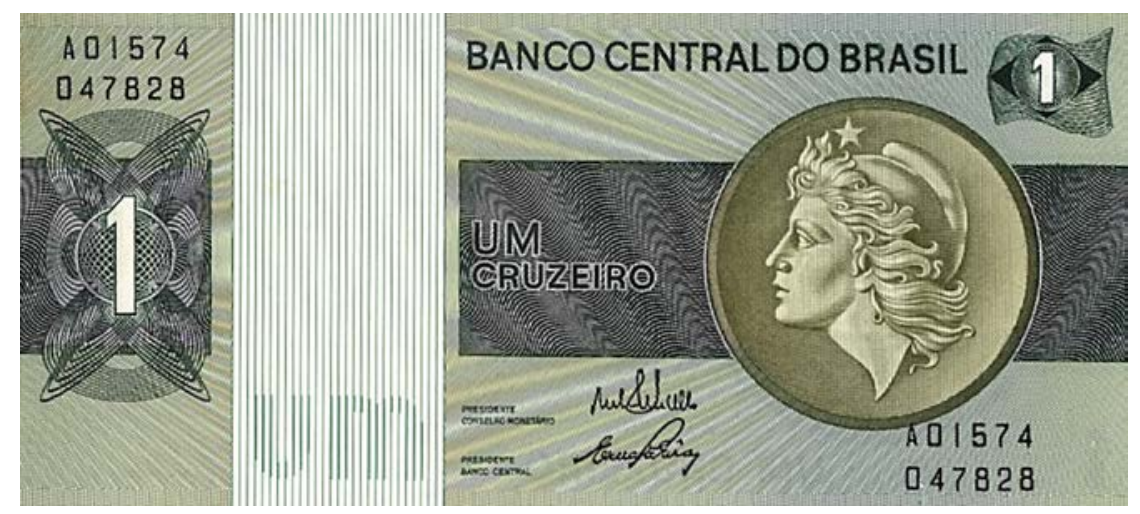




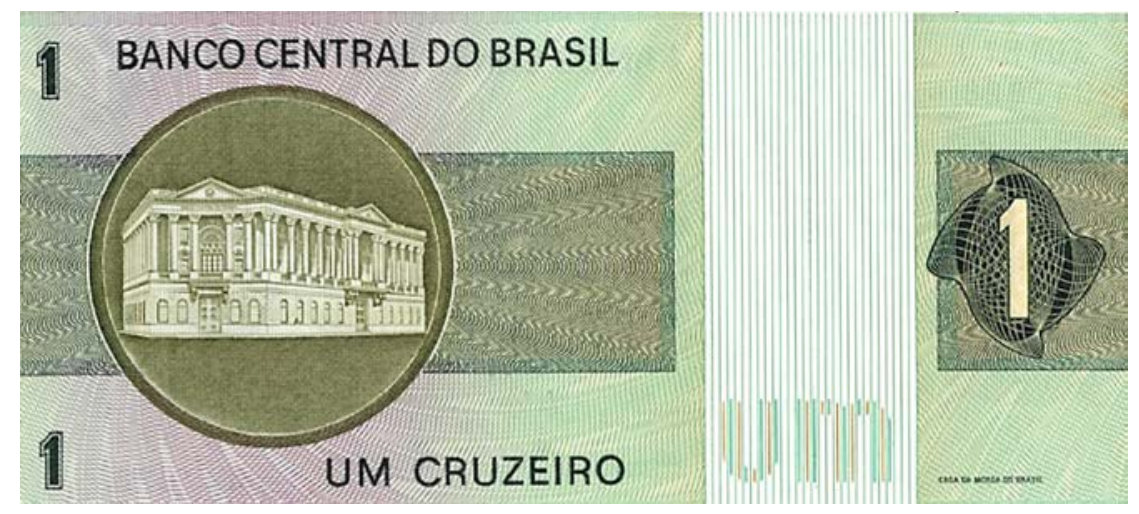

Figura 1 - Anverso e reverso da nota de um cruzeiro, de 1967.

Fonte: Elaborada pelos autores, a partir de cédula original.

Como apontado por TRIGUEIROS (1987), uma das inovações surgidas a partir do processo criativo de Aloisio foi a utilização do chamado efeito moiré. Tido como um defeito de impressão, resultado de um acidente visual entre as retículas que formam as cores, o moiré foi utilizado por Aloisio como gerador de padrões que dificultariam a reprodução ilegal das notas brasileiras.

De posse de um pequeno artefato formado por pequenos quadrados de filme transparente e papel onde se encontravam impressos padrões lineares similares, Aloisio percebeu que o desenho gerado por esse tipo de superposição já era em si um empecilho ao desenvolvimento de falsificações. Reproduzir um moiré provocado com exatidão se tornava quase impossível, ao menos, economicamente inviável (TABORDA \& LEITE, 2003, p. 193).

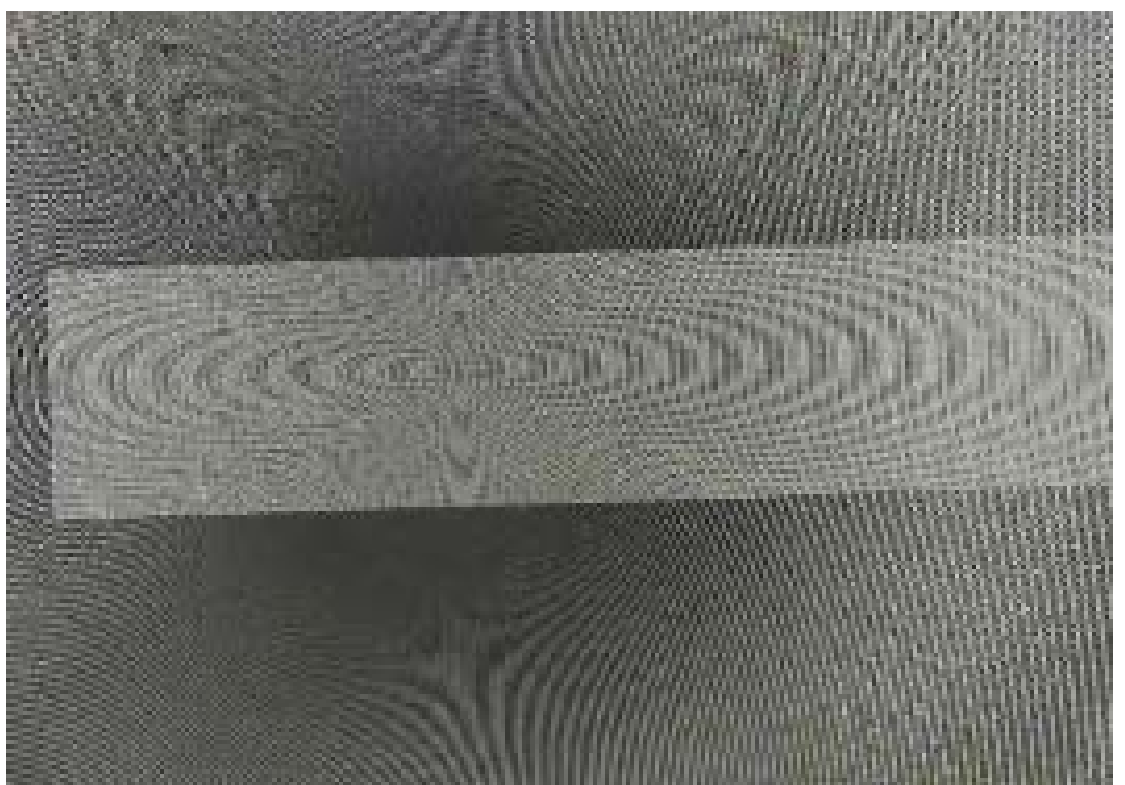

Figura 2 - Um dos estudos a partir do moiré para a família de cédulas do Cruzeiro. Fonte: Acervo do Museu de Valores, c. 1966. 


\section{A HISTÓRIA E AS ETNIAS DO BRASIL EM UMA CÉDULA: A NOTA DE QUINHENTOS CRUZEIROS}

No ano de 1972 o Brasil comemorava o Sesquicentenário de sua Independência de Portugal (1822/1972). Como parte das festividades, o Banco Central lançou a cédula de $\mathrm{Cr} \$ 500,00$ (quinhentos cruzeiros).

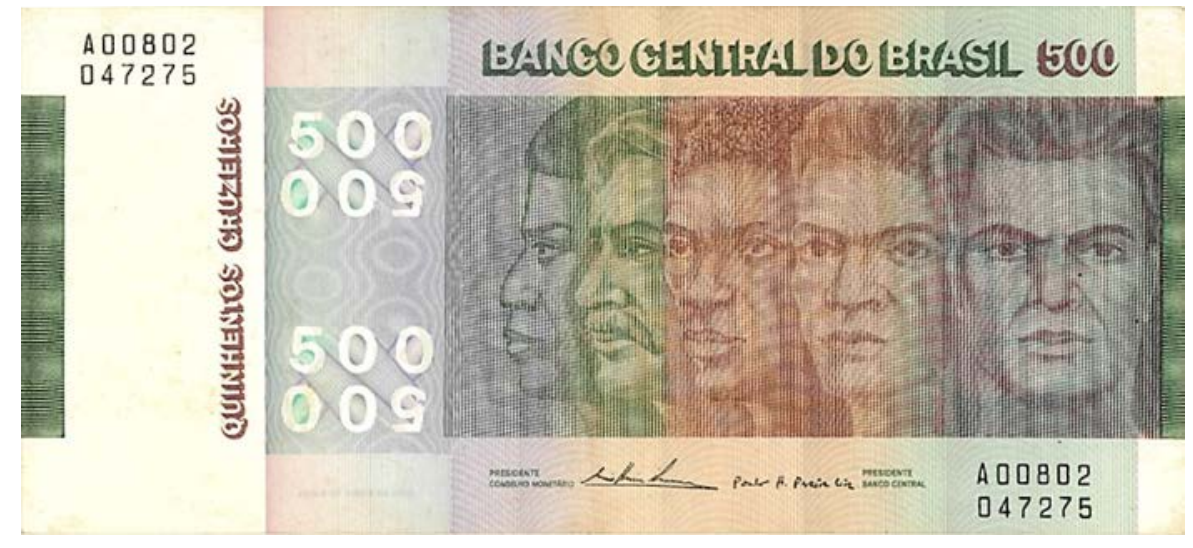

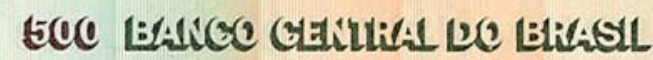

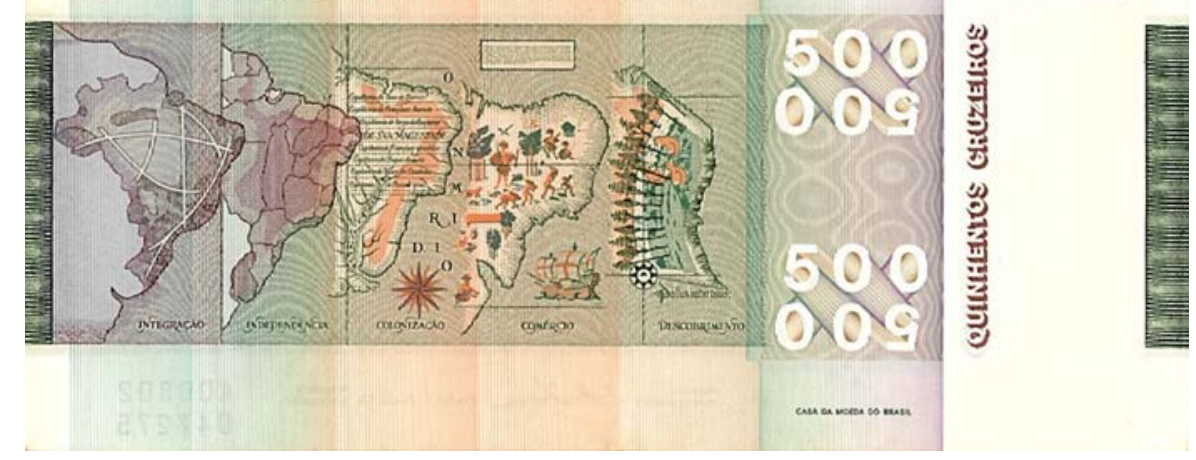

Figura 3 - Anverso e reverso da nota de quinhentos cruzeiros, de 1974.

Fonte: Elaborada pelos autores, a partir de cédula original.

A nota trazia elementos inovadores com relação ao padrão monetário nacional criado há pouco pelo próprio Aloisio. O autor, em entrevista a Germana de Lamare, originalmente publicada no Correio da Manhã, em março de 1972, afirmava

Nesta nota pude ir adiante, ainda mais. Não tem mais o retrato na sua formulação clássica. Ele é substituído por um painel gráfico baseado em uma soma entrelaçada de sistemas de linhas que constroem de uma maneira não realista uma sucessão de figuras que constituem o homem brasileiro: o índio, o branco, o preto e as suas diversas misturas... (LEITE, 2014, p. 60).

A nota de 500 cruzeiros foi a primeira cédula de dinheiro comemorativa do Brasil. Aloisio incluiu neste projeto exceções ao padrão de proposto em 1967, para a família do Cruzeiro.

As diferenças incluíam: 
a. no anverso, no lugar do retrato de uma personalidade histórica (ou da República, no caso da nota de um cruzeiro) a nota apresenta um gráfico composto por uma sequência de cinco rostos perfilados, em movimento - uma rotação que vai do perfil à visão frontal. Os rostos estão dispostos espacialmente com base em um ponto de vista histórico, utilizando-se como critério, para tal, a ordem de chegada ao Brasil. O gráfico retrata as etnias que compõem a base da sociedade brasileira, do indígena ao mestiço, passando pelo português, pelo negro e também demais imigrantes europeus;

b. no reverso, no lugar de prédios públicos de destaque (como o Banco Central do Brasil - no caso da nota de um cruzeiro - ou o Congresso Nacional - no caso da nota de cem cruzeiros), apresenta um gráfico composto por uma série histórica de mapas do Brasil: são reproduções que datam do descobrimento até a chegada ao período chamado de integração nacional, marco histórico do tecnicismo dos anos 1970 no país;

c. o tamanho da cédula, em comparação às cédulas de cruzeiro anteriores, é maior e tem outra proporção. Enquanto as dimensões das notas de um e cem cruzeiros eram $14,7 \times 6,7 \mathrm{~cm}$ e $16,7 \times 7,8 \mathrm{~cm}$, respectivamente, a nota de 500 cruzeiros media $17,2 \times 7,8 \mathrm{~cm}$;

d. as notas da série do cruzeiro tinham o predomínio de uma cor (a de um cruzeiro, por exemplo, era verde, enquanto a nota de cem cruzeiros era avermelhada) a nota de 500 cruzeiros apresentava mais contraste de cores (verde, roxo, vermelho, entre outras) entre seus elementos e dentro da composição, de maneira geral.

Além de todas essas contribuições, este projeto de papel-moeda foi preponderante para uma nova direção no sistema monetário brasileiro. 0 padrão apresentado em 1967 não mais seria continuado: as notas com novos valores faciais não seguiriam mais a série do Novo Cruzeiro e Aloisio Magalhães voltaria a surpreender com uma proposta inovadora para o dinheiro brasileiro. Essa nova proposta seria materializada na nova nota de mil cruzeiros, a chamada nota do Barão.

\section{5. "LÁ VAI BARÃO": A NOTA DE MIL CRUZEIROS}

A nova nota de dinheiro com valor de face de 1000 cruzeiros foi lançada em 1977. O elevado valor facial se fazia necessário em função dos efeitos causados pela desvalorização da moeda: o Cruzeiro valia cada vez menos e era necessário que se pudesse trabalhar com uma nota que valesse mais do que as antecessoras, para facilitar o manuseio do dinheiro.

Ao contrário das cédulas de 1, 5, 10, 50 e 100 cruzeiros, o projeto gráfico do novo papel moeda não se enquadrava dentro do então padrão vigente, idealizado pelo próprio Aloisio Magalhães, no final da década anterior: a nota de mil cruzeiros serviria de base para uma nova família de notas que estava por vir. O projeto, concebido por Aloisio, fora desenvolvido pelos designers João de Souza Leite e Washington Mesquita.

A nota trazia a efígie - neste caso, uma representação plástica da imagem de um personagem real - do Barão de Rio Branco, José Maria da Silva Paranhos Júnior. 0 barão, famoso pela resolução de conflitos territoriais internacionais, também era homenageado no reverso da nota: lá apresenta-se um mapa cartográfico estilizado, 
com suas curvas de nível ${ }^{1}$. Há, ainda, a ilustração central, que apresenta 0 espelhamento de um teodolito ${ }^{2}$. Entre as diversas atividades do Barão de Rio Branco, estava a atuação como geógrafo, profissão diretamente relacionada às ilustrações do reverso. Tanto o mapa, quanto o teodolito, estão integrados à composição de uma forma muito mais suave e menos contrastante do que a efígie no anverso. Isso faz com que a cédula tenha uma grande diferença em termos visuais entre suas duas faces: enquanto seu anverso é limpo, simples e contrastado, apresentando cores mais fortes e evidentes, em contraposição ao bege claro do papel moeda, seu reverso é denso, complexo e difuso, onde há a profusão de diversos elementos visuais e tons de cor.

Aloisio dividiu o trabalho em três planos: técnico, comunicação e design (TABORDA \& LEITE, 2003).

Em reunião no Banco Central, no Rio de Janeiro, presentes diretores do Banco e da Casa da Moeda, Aloisio traçou no quadro negro um programa de investigação. $O$ trabalho deveria ser desenvolvido em três planos simultâneos: o plano técnico, em que todo o conhecimento tecnológico deveria ser identificado em seu estado-daarte; o plano da comunicação, em que uma pesquisa indicaria possibilidades temáticas, e suas representações iconográficas, para o desenvolvimento do novo padrão, por fim, o plano do design, em que as informações tecnológicas deveriam ser interpretadas à luz das possibilidades de desenho que, em seu resultado, constituiriam um padrão adequado e com personalidade própria, a pautar não somente o desenho das cédulas a ser elaborado naquele exato momento, como também desenhos futuros. (TABORDA \& LEITE, 2003, p. 218)

Com relação ao plano técnico, é importante lembrar que o projeto sofreu severas críticas com relação à segurança. Com um cédula espelhada, reduz-se em cinquenta por cento a área de segurança e, consequentemente, a dificuldade imposta aos falsificadores para executarem seu trabalho. Isso, no entanto, não impediu que o projeto fosse levado adiante. A composição baseada no espelhamento da efígie foi utilizada em muitos outros projetos posteriores, mesmo sem a presença de Aloisio como projetista.

\footnotetext{
${ }^{1}$ Característica de documentos utilizados pela topografia para presentificar os diferentes níveis de altitude de determinado terreno, servindo como referência para a navegação em terrenos pouco conhecidos ou em que se deseja realizar algum tipo de intervenção humana.

2 Instrumento óptico de medida, utilizado pelos profissionais da topografia para realizar medidas e criar mapas cartográficos.
} 

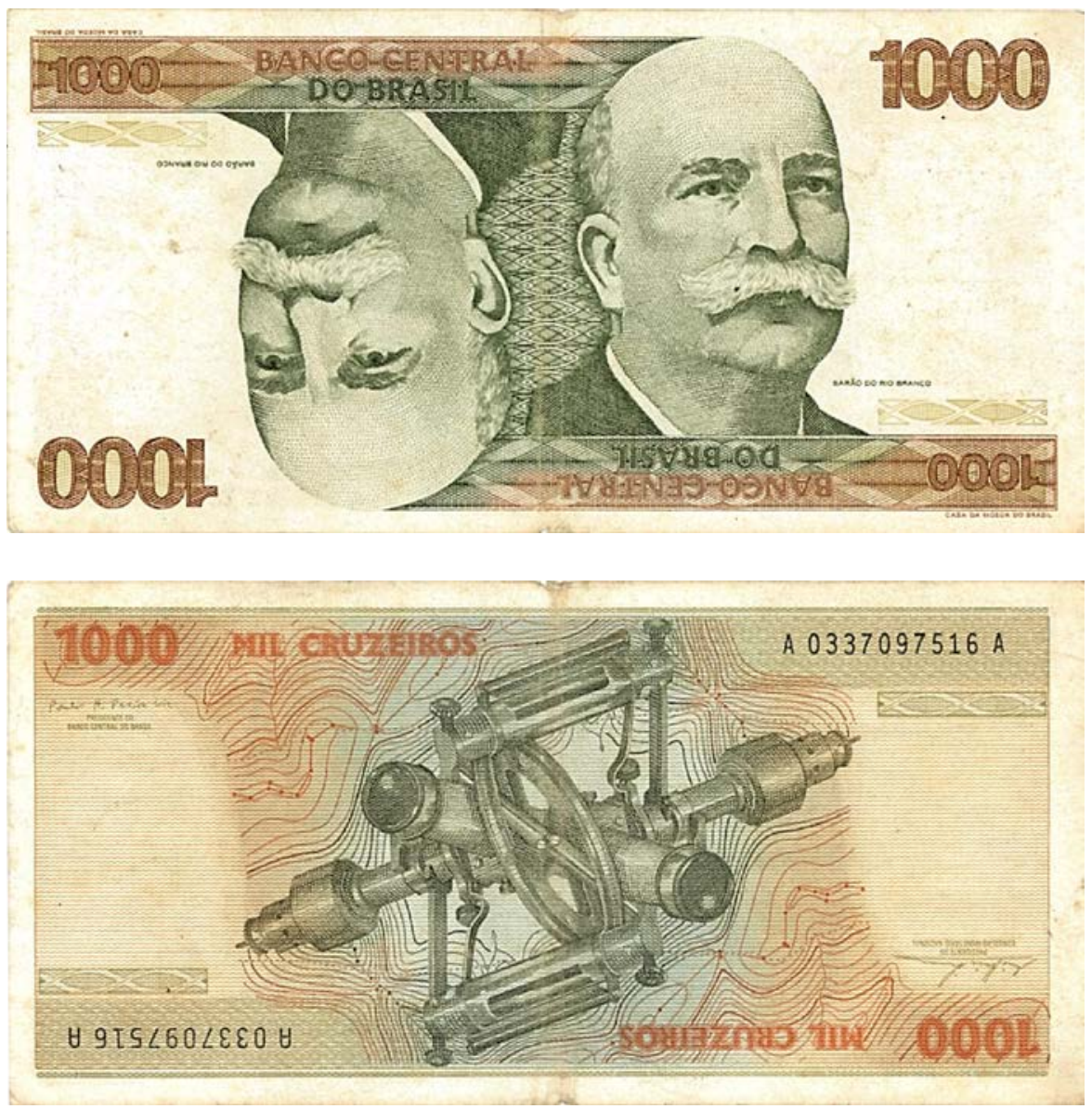

Figura 4 - Anverso e reverso da nota de mil cruzeiros, de 1977.

Fonte: Elaborada pelos autores, a partir de cédula original.

O projeto gráfico apresentou, no plano do design, uma série de inovações. A principal delas foi batizada de princípio formal do espelhamento, onde a cédula era dividida pela metade, e cada parte dessa divisão era o perfeito espelhamento da outra. Aloisio afirmava, em entrevista a Miriam Alencar para o Jornal do Brasil em 1978, que aquilo não era nenhuma novidade: na China da dinastia Te'tang, de 618 a 907, já havia dinheiro com figuras invertidas que possibilitavam a dupla leitura. Ainda segundo ele, na Europa Ocidental, a impressão de cartas de baralho precedeu a impressão das cédulas de dinheiro (LEITE, 2014). Ao se analisar a proposta de Magalhães para o projeto gráfico do dinheiro, percebe-se que, apesar de seu esforço e exercício de humildade, aquela era sim, uma inovação e tanto. E não apenas pela ideia de usar figuras espelhadas - que resultavam numa nota que não tinha lado, ou melhor, estava sempre na posição correta de leitura para o seu portador - mas pelo projeto gráfico em si, extremamente funcional e, ao mesmo tempo, marcante.

Por conta da efígie, a nota passou a ser chamada de Barão. Tal alcunha desencadeou, no senso comum e na cultura popular, o uso da palavra "barão" como sinônimo da quantidade mil, principalmente ao se falar em valores. Dizer que "isso custa mais de um barão" era o mesmo que dizer que custava mais de 1000 cruzeiros. Outra expressão bastante popular, criada na época era "lá vai barão!". Quando algo custaria muito dinheiro, ou daria muito gasto, era comum se usar tal expressão: "meu carro estragou, vou ter que mandar para o conserto. E lá vai barão!". Posteriormente e 
por anos a fio - quando a moeda já não era mais o cruzeiro - o uso da palavra "barão" seguiu como sinônimo da quantidade de mil.

\section{CONSIDERAÇÕES FINAIS}

O trabalho e a influência de Aloisio Magalhães no novo padrão monetário nacional não se limitaram, simplesmente, ao desenho das novas notas. Magalhães foi além, tomando as rédeas no processo de aprendizagem que se fazia necessário como pré-requisito para a produção local das cédulas de dinheiro.

Demonstrando na prática a importância de uma presença protagonista do designer no processo produtivo, suas ideias auxiliaram o país a entrar em uma nova fase de autossuficiência na produção de papel-moeda. Aloisio utilizou o desenho industrial como ferramenta de transformação social e cultural, aliado ao fato de ter sido ele um grande pesquisador e promotor da cultura brasileira.

\footnotetext{
O chamado processo de desenvolvimento de uma cultura não se mede somente pelo progresso e pelo enriquecimento econômico, mas por um conjunto mais amplo e sutil de valores. [...] só através da análise e de estudos interdisciplinares, se poderá alcançar a compreensão do conjunto de fatores que serão capazes de configurar um crescimento verdadeiramente harmonioso. Aos fatores econômicos [...] foram acrescentados os fatores sociais e, já agora, a compreensão do todo cultural. O Desenho Industrial surge [...] como uma disciplina capaz de se responsabilizar por uma parte significativa deste processo. Porque não dispondo nem detendo um saber próprio, utiliza vários saberes que se ocupam da racionalização e da medida exata - os que dizem respeito à ciência e à tecnologia - e de outro, daqueles que auscultam a vocação e a aspiração dos indivíduos - os que compõem o conjunto das ciências humanas (MAGALHÃES, 1998, p. 12)
}

O concurso fechado para a escolha de um novo projeto para as notas de papel brasileiro foi logo entendido por Aloisio Magalhães como algo muito maior do que simplesmente um trabalho de design. Apresentava-se ali uma grande oportunidade de quebra de paradigma. E a quebra foi tamanha e de tão forte impacto que seu legado perdura ainda hoje.

As atuais notas de Real ainda guardam, em seu projeto gráfico, forte influência do desenho de Aloisio Magalhães, por exemplo. Notas de dinheiro de outros países sofreram influência do design brasileiro, contrastando com o papel-moeda pré-Aloisio totalmente importado e dependente de fornecedores externos. Importação essa que, além de não fomentar a indústria nacional, ainda apresentava um custo elevadíssimo para dar conta de suprir a demanda do dinheiro circulante em nosso país.

A partir de seu trabalho, basicamente dois importantes resultados puderam ser mapeados: em primeiro lugar, finalmente o dinheiro brasileiro tinha a cultura brasileira e a realidade de nosso país entre os referenciais que serviram de base para a sua composição. Em segundo lugar, finalmente o povo de nosso país estava, de fato, representado em seu próprio papel moeda, este impregnado de brasilidade, design e cultura nacional. 


\section{REFERÊNCIAS}

DENIS, R. C. Uma introdução à história do design. São Paulo: Edgar Blücher, 2000.

LEITE, J. S. (Org.). Encontros: Aloisio Magalhães. Rio de Janeiro: Beco do Azougue, 2014

MAGALHÃES, A. O Que o Desenho Industrial Pode Fazer pelo País? In: Arcos: Design, Cultura Material e Visualidade, Rio de Janeiro: ESDI, 1998, v. I, n. único, p. 8-13.

. E Triunfo? A Questão dos Bens Culturais no Brasil. Rio de Janeiro: Nova Fronteira; Fundação Roberto Marinho, 1997.

SILVA JUNIOR, A. F. Uma etnografia do dinheiro: os projetos gráficos de papel-moeda no Brasil após 1960. 2008. 337 f. Tese (doutorado) - Universidade do Estado do Rio de Janeiro, Instituto de Filosofia e Ciências Humanas.

TABORDA, F.; LEITE, J. S. A Herança do Olhar: o Design de Aloisio Magalhães. Rio de Janeiro: Artviva/SENAC, 2003.

TRIGUEIROS, F. S. Dinheiro no Brasil. 2a . Ed. Rio de Janeiro: Léo Christiano Editorial, 1987. 